\title{
RESENHAS
}

\section{ENSINO TÉCNICO EM PORTUGAL E NO BRASIL: UMA PERSPECTIVA DA REALIDADE}

Luís Pardal, Maria Laura Puglisi Barbosa

Franco, Carlos Dias, Gláucia Torres Franco

Novaes, Clarilza Prado de Sousa

Aveiro: Universidade de Aveiro, 2003,

Onsino técnico e profissional, bem como o ensino médio regular, são focalizados neste livro, com base em estudos de caso realizados em Portugal e no Brasil, consideradas as devidas diferenças entre ambos os países. Os eixos de análise contexto, equipes de gestão, corpo docente e alunos - são abordados com grande coerência, permitindo que os pontos convergentes e divergentes apareçam com clareza no estudo realizado.

A discussão sobre as características históricas, políticas e sociais que permeiam a constituição dos diferentes sistemas de ensino ilumina o cenário recente no qual são implementadas as políticas para a área, nem sempre desenhadas para atender as especificidades regionais e locais, tendo em vista a prevalência de diretrizes homogeneizadoras preconizadas por agências internacionais de financiamento.

O livro, resultado de pesquisa realizada em conjunto entre a Universidade de Aveiro e o Programa de Estudos Pós-Graduados em Psicologia da Educação, da Pontifícia Universidade Católica de São Paulo, apresenta oito capítulos, que abordam os tópicos: tendências do ensino técnico e profissional; a realidade portuguesa atual; a escola: contextos e condições; os atores: caracterização e desempenho; a formação: realidade, expectati- vas e níveis de satisfação; o currículo e o seu desenvolvimento; ligação com o mundo do trabalho e, finalmente, escolas de formação profissional e ensino médio regular: estudos de caso no Brasil.

Sem se constituir em estudo comparado, a análise compartilhada por pesquisadores do Brasil e de Portugal, sem dúvida, enriquece as questões sobre essa modalidade de ensino, foco de debate internacional em razão das reformas em curso.

Na literatura da área, grosso modo, as críticas e os debates sobre o ensino médio giram em torno da análise sobre os condicionantes dessas reformas, tendo como pano de fundo o mundo contemporâneo em seus diversos aspectos sociais, econômicos, políticos, demográficos, raciais e étnicos. Em alguns estudos, esses condicionantes são analisados como uma influência direta no desenho proposto e adotados por inúmeros governos para as reformas do ensino médio. Em outros, aparecem apenas como referência para avaliação de políticas regionais que adotam determinadas diretrizes em detrimento de outras, tendo em vista as diferentes inserções dos países no cenário internacional.

De qualquer forma, as perspectivas de investigação, centradas na análise de cenário internacional, regional ou nacional, são fundamentais para a construção de um campo crítico de teorias e debates, porém, por sua própria metodologia, excluem a voz dos atores escolares, uma vez que se limitam à análise do desenho das políticas públicas com base em documentos, em fontes oficiais, no conjunto normativo-legal e/ou na discussão dos próprios condicionantes políticos e sociais.

Mais raros são os estudos que incluem a observação dos atores, a realização de entrevistas e a análise de documentos oficiais e medidas legais que informam a agenda das políticas da área. Nes- 
se sentido, é importante destacar a contribuição fundamental deste livro quando confronta o discurso oficial, com base na análise das políticas educacionais de ambos os países, e a realidade escolar.

O objetivo do trabalho foi plenamente alcançado, pois a pertinência da abordagem metodológica, a abrangência do estudo e a análise realizada permitiram aprofundar a discussão sobre as trajetórias do ensino técnico e profissional e do ensino médio regular. Os autores conduziram a pesquisa respeitando a diversidade e a dimensão dos problemas de cada país, sem abrir mão da análise das políticas que têm estruturado historicamente esse nível de ensino. Além disso, os pesquisadores abordaram e buscaram interpretar "até que ponto se instalam, na prática, as possibilidades e as dificuldades de tais políticas educacionais", investigando, no cotidiano escolar, como se dá a formação dos alunos e quais "são os significados que os educadores responsáveis por esta formação atribuem a esta educação".

Em Portugal, foram realizados estudos de caso em cinco escolas localizadas em diferentes regiões do país, que apresentavam características distintas: algumas existentes há mais de cem anos; outras, construídas especificamente para o ensino profissional; outras, ainda, adaptadas recentemente

a esta modalidade de ensino. No Brasil, foram realizados três estudos de caso: um, em escola da rede de ensino do Estado de São Paulo, que oferece ensino técnico profissionalizante de nível médio, pertencente ao Centro Paula Sousa; o segundo, realizado em escola que oferece o ensino técnico profissionalizante de nível médio do Serviço Nacional de Aprendizagem Comercial - Senac -, que compõe o denominado sistema "S" de ensino profissional, finalmente, o terceiro, realizado em escola de ensino médio regular, nos períodos diurno e noturno.

O livro insere-se no debate que está posto sobre a complexidade de que se reveste a implementação das reformas do ensino médio em âmbito internacional e aponta, com mérito, questões que precisam ser aprofundadas em estudos posteriores, configurando-se, portanto, como leitura obrigatória para todos aqueles que tenham algum interesse em realizar pesquisas sobre o tema.

$$
\begin{array}{r}
\text { Angela Maria Martins } \\
\text { Programa de Mestrado em Educação da } \\
\text { Universidade Católica de Santos e } \\
\text { Departamento de Pesquisas Educacionais da } \\
\text { Fundação Carlos Chagas } \\
\text { amartins@fcc.org.br }
\end{array}
$$

\section{QUALIFICAÇÃO PROFISSIONAL: UMA TAREFA DE SÍSIFO}

Claudia Mattos Kober

Campinas: Autores Associados, 2004,

O livro de Claudia Mattos Kober tem como objetivo implícito a desconstrução do consenso que vincula linearmente educação, qualificação, emprego e desenvolvimento. Ou seja, procura desmitificar a idéia de que, quanto mais educado e qualificado for um indivíduo, maiores serão os retornos, não só em termos pessoais - maiores chances de inserir-se e se recolocar no mercado de trabalho (de tornar-se "empregável", para usar o jargão atual), de receber aumentos salariais, promoção etc. -, como também sociais: aumentar a produtividade das empresas e, conseqüentemente, gerar desenvolvimento econômico e social para os países. Apesar de essa idéia não ser nova - a teoria do capital humano, já a defendia nos anos 60 -, a força que ela adquire na atualidade, em um contexto de acirrada competição devido às altas 